\title{
Motivational theory of human robot teamwork
}

\begin{abstract}
This paper presents a theory that allows us to better understand motivation in human-robot teamwork. Teamwork with robots often involves both physical and mental activities. This implies that motivation might be particularly important to the success of human robot teams. Unfortunately, there is much we do not know with regards to the role of motivation in effective teamwork with robots. In this paper we propose the "Motivational Theory of Human-Robot Teamwork" to better understand teamwork in human-robot teams. In doing so, we leverage the research on robot personality.
\end{abstract}

Keywords: robots robot teammates, teaming with robots, human robot collaboration, teamwork with robots, human robot teams, motivation, theory, humanization of robots, robot coworkers
Volume 4 Issue 4 - 2018

\section{Lionel P Robert}

School of Information, University of Michigan, USA

Correspondence: Lionel P Robert, School of Information,

University of Michigan, USA, Tel 734-764-5296

Fax (734) 615-3587, Email Iprobert@umich.edu

Received: June 20, 2018 | Published: July 20, 2018

\section{Abbreviations: HRI, human robot interaction}

\section{Introduction}

Human-robot teams, teams of humans and robots, are being deployed across many work settings. ${ }^{1}$ This is reflected in the increased use of robots in the workforce, where they are expected to replace as much as half the workforce in 10-20 years. ${ }^{2-4}$ The ability to effectively integrate robots into teams can either hinder or facilitate successful teamwork. ${ }^{5}$ However, advances in technology have far outpaced our theorizing with regard to the relationships between humans and robots. ${ }^{5-7}$ Motivational theories of teamwork highlight the role of effort or a lack of effort when it comes to promoting effective teamwork. Motivation is defined as an individual or team's intention of achieving a goal, which is followed by an allocation of effort to achieve this goal. ${ }^{8}$ In this paper, more effective teamwork is assumed to lead to better performance, team satisfaction and viability. All three outcomes are widely recognized as important measures of successful teamwork. ${ }^{7}$ Motivational theories have been used to explain both individual and team performance. ${ }^{9-12}$ Working with robots often involves both physical and mental activities. This implies that motivation might be particularly important to the success of these teams. Unfortunately, despite the potential importance there is much we do not know with regard to the role of motivation in effective teamwork with robots. ${ }^{13-15}$ With this in mind, our goal in this paper is to advance our understanding of teamwork with robots through a motivational view (Figure 1). In this paper we propose the "Motivational Theory of Human-Robot Teamwork" to better understand teamwork in human-robot teams. In doing so, we leverage the research on robot personality. Personality has consistently demonstrated an impact on the actions and outcomes of teamwork among humans and with robots. ${ }^{16}$ In this paper we present a theory that allows us to better understand motivation in human-robot teamwork. Here we make three key contributions. First, we theoretically integrate the literature on human-robot personality with theories of individual and team motivation. In doing so, we put forth a more coherent explanation of the relationship between prior HRI research on personality and future HRI research on motivation. Second, we identify the robot's competence as a key theoretical mechanism linking robot personality and human motivation in human-robot teams. Finally, the proposed theory goes beyond the individual level of analysis to explicate the mechanisms driving motivation at the team level as well linking both individual and team outcomes. The following section presents the general relationships between a robot's personality traits, motivation, and individual and team outcomes. This first set of propositions presents the impacts of the robot's personality on a human's perceptions of its competence. The next section discusses the effects of the robot's competence on human motivation. This is followed by propositions related to the impact of motivation on individual and team outcomes. Finally, we conclude the paper.

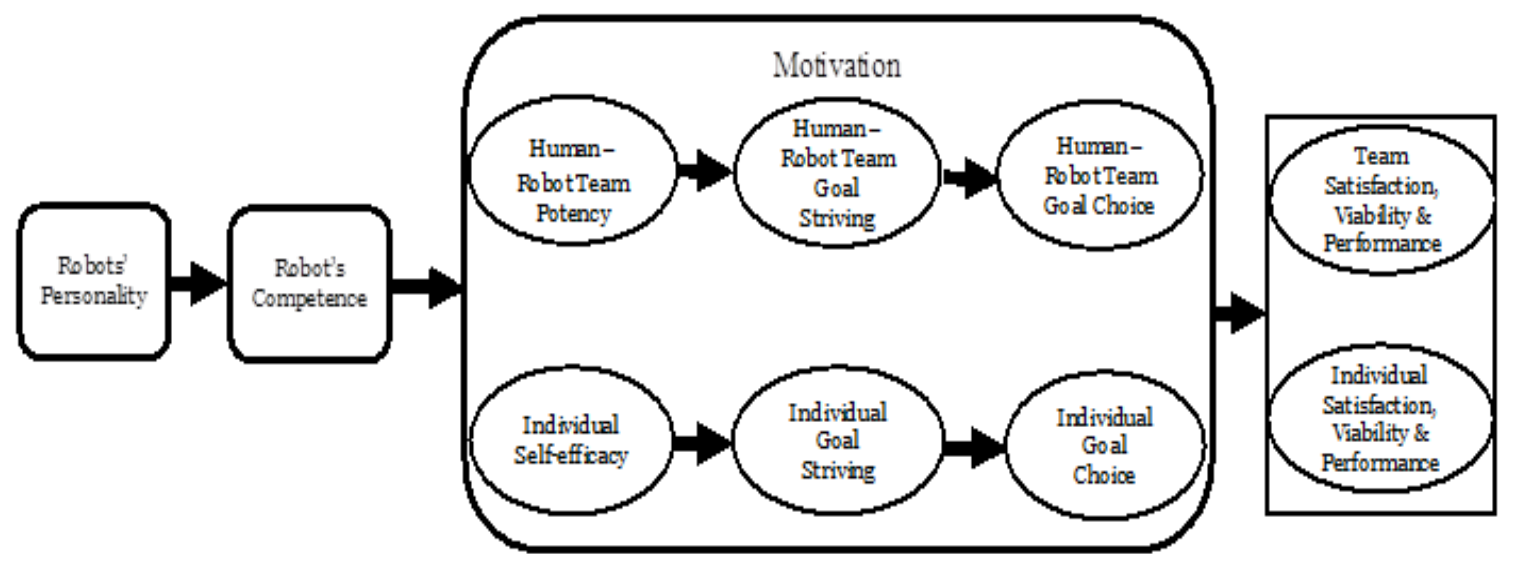

Figure I Theoretical Model. 


\section{Theoretical model}

\section{Emotional stability}

A robot's display of emotional stability should positively impact a human's perception of its competence. Emotional stability refers to the degree to which someone is calm, well-adjusted, secure and selfconfident. ${ }^{17,18}$ It reflects the ability of an individual to remain calm in the face of adversity or a difficult situation. ${ }^{18}$ Emotional stability is normally viewed as a positive trait. This is in part because it has been associated with the positive expectation that an individual is capable of getting things done. ${ }^{19}$ This is in stark contrast to neuroticism, which is associated with anxiety, depression, anger, worry and insecurity. ${ }^{20}$ Generally, research has posited and found several examples of emotional stability being positively related to teamwork with robots..$^{21,22}$

Proposition 1a: Robot's display of emotional stability is positively related to a human's perception of its competence.

Proposition 1b: Robot's display of emotional stability is positively related to the team's perception of its competence.

\section{Extraversion}

A robot's display of extraversion should facilitate human's perception of its competence. Extraversion represents the degree to which someone is outgoing or sociable with others. ${ }^{22}$ Extraverts are often assertive and more likely to initiate and carry out team tasks. ${ }^{17}$ Extraversion has also been associated with better cognitive abilities like memory, technical knowledge and strong communication skills. ${ }^{23}$ Extraversion has been positively associated with better interpersonal relationships and performance outcomes among humans and robots (for a review see Robert). ${ }^{16}$

Proposition 2a: Robot's display of extraversion is positively related to a human's perception of its competence.

Proposition 2b: Robot's display of extraversion is positively related to the team's perception of its competence.

\section{Openness to experience}

A robot's display of openness to experience should be positively associated with a human's perception of its competence. Openness to experience is the extent to which someone is imaginative and broadminded. ${ }^{24}$ It is often used to reflect the intellectual, cultural and creative interest of individuals. ${ }^{18}$ Although openness to experience is associated with many positive attributes, flexibility and the ability to learn quickly are often touted as its most salient benefits to teamwork. ${ }^{17}$ Openness to experience has been positively related to individual and team learning, satisfaction and performance. ${ }^{19,25,26}$

Proposition 3a: Robot's display of openness to experience is positively related to a human's perception of its competence.

Proposition 3b: Robot's display of openness is positively related to the team's perception of its competence.

\section{Agreeableness}

A robot's display of agreeableness should be positively associated with a human's perception of its competence. Agreeableness often reflects whether someone is cooperative or friendly. ${ }^{18}$ Agreeableness is often synonymous with words like kindness, trust and warmth. ${ }^{17}$ Agreeable individuals are also considered to be more honest and supportive. ${ }^{27}$ Individuals low in agreeableness are consider to be uncaring, critical, unsupportive and uncooperative. ${ }^{28}$ This explains why agreeableness has been a strong predictor of individual and team performance in teams with and without robots..$^{29}$

Proposition 4a: Robot's display of agreeableness is positively related to a human's perception of its competence.

Proposition 4b: Robot's display of agreeableness is positively related to the team's perception of its competence.

\section{Conscientiousness}

A robot's display of conscientiousness should be positively associated with a human's perception of its competence. Conscientiousness is the extent to which someone is thoughtful and self-aware. ${ }^{27}$ It reflects careful, deliberative and responsible behavior. ${ }^{18}$ Individuals high in conscientiousness have been shown to be hardworking, well-prepared, organized and reliable. ${ }^{17}$ Conscientiousness has been found to be positively associated with individual satisfaction and performance..$^{20}$ Similarity, it has also been strongly related to team performance and satisfaction. . $^{18,27,30,31}$ There has been less work on the topic in the HRI literature when compared to other types of personality. ${ }^{16}$ However, Meerbeek et al., ${ }^{32}$ did examine how robots could display conscientiousness. Nonetheless, similarly to the impact of human's displaying conscientiousness, we would expect it to lead to positive perception of the robot's competence.

Proposition 5a: Robot's display of conscientiousness is positively related to a human's perception of its competence.

Proposition 5b: Robot's display of conscientiousness is positively related to the team's perception of its competence.

\section{Theorizing motivation in human-robot teams at the individual level}

Motivation can be described as the willingness of an individual to exert and sustain effort. ${ }^{33}$ It reflects those forces that focus, propel and sustain effort. ${ }^{8}$ Most human behavior begins with a goal or objective. ${ }^{34}$ Theories of motivation help explain how goals and objectives are developed and maintained throughout an activity. ${ }^{35}$ In the context of a team, that willingness to exert effort can be directed toward accomplishing one's own role or helping others accomplish their roles on behalf of the team. ${ }^{33}$ Similar positive effects of motivation have been found in the few studies linking it to personality in the HRI literature. ${ }^{13,14}$ Theories of motivation posit that individual motivation comprises three core components: goal choice, goal striving and self-belief in goal attainment. ${ }^{16}$ Goal choice represents the process of deciding which objectives to pursue while goal striving reflects the actual effort allocated and sustained to pursue the chosen goals or objectives. ${ }^{11}$ Overall self-belief in efficacy helps drive goal choice, which in turn influences the amount of effort and persistence individuals allocate toward achieving their objective. ${ }^{11,37}$ Taken together, self-efficacy, goal choice and goal striving make up the motivational process that explains the amount of effort an individual allocates toward achieving a goal. ${ }^{10}$

Proposition 6a: An individual's perception of the robot's competence in teams working with robots is positively related to that individual's motivation in the team: self-efficacy, goal choice and goal striving.

Proposition 6b: An individual's motivation in teams working with robots is positively related to their outcomes: performance, willingness 
to continue to work with the team (i.e. viability) and satisfaction.

\section{Theorizing motivation in human-robot teams at the team level}

Research has found similar effects at the team level., $93,38,38,39$ However, several differences between the team and individual motivational processes should be highlighted. Team self-efficacy is related but clearly distinct from individual self-efficacy. It can differ in the sense that individuals might not believe that they as an individual can achieve their objective but that the team can, or vice versa. At the team level, the degree to which all members believe they can achieve their team goals helps determine which goals as a team they choose to take on $^{33}$ Team goal choice represents the degree to which the team agrees on which set of objectives to pursue, while team goal striving reflects the actual effort the team as a whole allocates and sustains to pursue the team's chosen goals or objectives. ${ }^{11}$ Team goal choice has been found to be positively related to the amount of effort the team allocates and maintains to achieve its objectives. ${ }^{33}$ Goal striving at the team level has also been positively related to team performance. ${ }^{40}$

Proposition 7a: Team members' perception of their robot's competence is positively related to that team's motivation: selfefficacy, goal choice and goal striving.

Proposition 7b: Motivation in teams working with robots is positively related to individual team members' outcomes: performance, viability and satisfaction.

\section{Conclusion}

Overall, the purpose of this paper has been to present the Motivational Theory of Human-Robot Teamwork. Drawing from a large body of literature on motivation and human-robot interaction, the model seeks to explain how team and individual motivational factors impact human and robot teams. The theoretical model is a first step in advancing our understanding of human-robot teamwork. However, the theoretical model is far from comprehensive and more work is needed with regard to both theoretical development and empirical verification.

\section{Acknowledgements}

None.

\section{Conflict of interest}

The author declares there is no conflict of interest.

\section{References}

1. You S, Robert LP. Human-robot similarity and willingness to work with a robotic co-worker. In Proceedings of the $13^{\text {th }}$ Annual ACM/IEEE International Conference on Human Robot Interaction; 2018 March 5-8; Chicago, IL, USA; 2018.

2. Conley W. US army to deploy remote-controlled robotic infantry in the field within 5 years? Slash Gear. 2014

3. Gurchiek K. Human-looking robots entering the workplace, HR News. 2015 .

4. Qureshi M O, Syed RS. The impact of robotics on employment and motivation of employees in the service sector, with special reference to health care. Saf Health Work. 2014;5(4):198-202.
5. You S, Robert L. Emotional attachment, performance, and viability in teams collaborating with embodied physical action (EPA) robots. Journal of the Association for Information Systems. 2018;19(5):377-407.

6. Jung, M, Hinds P. Robots in the wild: A time for more robust theories of human-robot interaction. ACM Transactions on Human-Robot Interaction. 2018;7(1):2.

7. You S, Robert LP. Teaming up with robots: An IMOI (inputs-mediatorsoutputs-inputs) framework of human-robot teamwork. International Journal of Robotic Engineering. 2017:2(3).

8. Kanfer R, Chen G, Pritchard RD. Work motivation: Past, present, and future. New York, NY, Routledge; 2008.

9. Chen G, Kanfer R. Towards a systems theory of motivated behavior in work teams. Research in organizational behavior. 2016;27:223-267.

10. Klein HJ, Austin JT, Cooper JT. Goal choice and decision processes. In R Kanfer, G Chen, R Pritchard, editors. Work motivation: Past, present, and future. New York, London; Routledge/Taylor \& Francis Group; 2008:101-150

11. Parker SK, Bindl UK, Strauss K. Making things happen: A model of proactive motivation. Journal of Management. 2010:36(4):827-856.

12. Srinivasan SS, Maruping L, Robert L. Mechanisms underlying social loafing in technology teams: An Empirical Analysis. In ICIS 2010 Proceedings. 2010:183.

13. Andrist S, Mutlu B, Tapus A. Look Like Me. Matching Robot Personality via Gaze to Increase Motivation, in Proceedings of the $33^{\text {rd }}$ Annual ACM Conference on Human Factors in Computing Systems, Seoul, Republic of Korea. 2015:3603-3612.

14. Dang THH, Tapus A. Stress game: The role of motivational robotic assistance in reducing user's task stress. International Journal of Social Robotics. 2015;7(2):227-240.

15. Robert LP, You S. Human-robot interaction in groups: theory, method, and design for robots in groups. Proceedings of the $18^{\text {th }} \mathrm{ACM}$ International Conference on Supporting Group Work. 2014 November 9-12, Sundial Island, FL, USA ACM Digital Library; 2014.

16. Robert LP. Personality in the human robot interaction literature: a review and brief critique. In Proceedings of the $24^{\text {th }}$ Americas Conference on Information Systems, 2018 Aug 16-18, New Orleans, LA.

17. Driskell JE, Goodwin GF, Salas E, et al. What makes a good team player? Personality and team effectiveness. Group Dynamics. 2006;10:249-271.

18. Peeters MG, Van Tuijl HFJM, Rutte CG, et al. Personality and team performance: a meta-analysis. European Journal of Personality. 2006;20(5):377-396.

19. Molleman E, Nauta A, Jehn KA. Person-job fit applied to teamwork. A multilevel approach. Small Group Research. 2004;35:515-539.

20. Judge TA, Heller D, Mount MK. Five-factor model of personality and job satisfaction: A meta-analysis. J Appl Psychol. 2002;87(3):530-541.

21. Hwang J, Park T, Hwang W. The effects of overall robot shape on the emotions invoked in users and the perceived personalities of robot. Appl Ergon. 2013;44(3):459-471.

22. Mileounis A, Cuijpers RH, Barakova EI. Creating Robots with Personality: The Effect of Personality on Social Intelligence, in Proceedings of the International Work-Conference on the Interplay Between Natural and Artificial Computation, Cham. Springer; 2015:119132 .

23. Rhee J, Parent D, Basu A. The influence of personality and ability on undergraduate teamwork and team performance. SpringerPlus. 2013;2(1):16. 
24. Juhász M. Application of Five Factor Model in the personnel selection and the performance rating: Influence the criteria changes on the predictive validity and supervisory rating (doctoral thesis). BME-ELTE, Budapest. 2002.

25. McCrae RR, Costa PT. Personality trait structure as a human universal. Am Psychol. 1997;52(5):509-516.

26. Birnbaum GE, Mizrahi M, Hoffman G, et al. Machines as a source of consolation: robot responsiveness increases human approach behavior and desire for companionship. In Proceedings of the Eleventh ACM/ IEEE International Conference on Human Robot Interaction, IEEE Press; 2016:165-171.

27. Hollenbeck JR, Moon H, Ellis APJ, et al. Structural contingency theory and individual differences: Examination of external and internal personteam fit. J Appl Psychol. 2002;87(3):599-606.

28. Tasa K, Sears GJ, Schat AC. Personality and teamwork behavior in context: the cross-level moderating role of collective efficacy. Journal of Organizational Behavior. 2011;32(1):65-85.

29. McCrae RR, Costa PT. Updating Norman's 'adequate taxonomy': Intelligence andpersonality dimensions in natural language and questionnaires. J Pers Soc Psychol. 1985;49(3):710-721.

30. Brandstetter J, Beckner C, Sandoval EB, et al. Persistent lexical entrainment in HRI. 2017:63-72.

31. Hurtz GM, Donovan JJ. Personality and job performance: The Big Five revisited. J Appl Psychol. 2000;85(6):869-879.

32. Morgeson FP, Reider MH, Campion MA. Selecting individuals in team settings: The importance of social skils, personality characteristics, and teamwork knowledge. Personnel Psychology. 2005;58:583-611.
33. Meerbeek B, Hoonhout J, Bingley P, et al. The influence of robot personality on perceived and preferred level of user control. Interaction Studies. 2008;9(2):204-229.

34. Chen G, Kanfer R, DeShon RP, et al. The motivating potential of teams: Test and extension of Chen and Kanfer's (2006) cross-level model of motivation in teams. Organizational Behavior and Human Decision Processes. 2009;110(1):45-55.

35. Kanfer R. Motivation theory and industrial and organizational psychology. In M.D. Dunnette \& LM Hough, editors. Handbook of industrial and organizational psychology. Consulting Psychologists Press, Palo Alto, CA; 1990

36. Kanfer R, Ackerman PL. Motivation and cognitive abilities: An integrative/aptitude-treatment interaction approach to skill acquisition. Journal of Applied Psychology. 1989;74(4):657-690.

37. Chen G, Thomas B, Wallace JC. A multilevel examination of the relationships among training outcomes, mediating regulatory processes, and adaptive performance. J Appl Psychol. 2005.90(5):827-841.

38. Chen G, Farh JL, Campbell-Bush EM, et al. Teams as innovative systems: Multilevel motivational antecedents of innovation in R\&D teams. J Appl Psychol. 98(6):1018-1027.

39. $\mathrm{Hu}$ J, Liden RC. Antecedents of team potency and team effectiveness: an examination of goal and process clariy and servant leadership. J Appl Psychol. 2011;96(4):851-862.

40. Hu J, Liden R. Making a difference in the teamwork: Linking team prosocial motivation to team processes and effectiveness. Academy of Management Journal. 2014:58(4):1102-1127. 